\title{
Qualidade da educação e política de remuneração docente: quais as implicações dessa relação?
}

Quality in education and teacher remuneration policy: what are the implications of this relation?

\section{Resumo}

Este artigo versa sobre a remuneração docente como um dos aspectos que compõem as condições de trabalho do professor e defende que se trata de item de suma importância para a qualidade da edu202 cação, embora não seja exclusivo. Para discutir esse argumento, o artigo está organizado em três partes. A primeira apresenta o debate sobre a qualidade da educação e a política de valorização docente, com destaque para a remuneração, abordando tanto aspectos conceituais como legais, além de pesquisas acadêmicas. A segunda discute alguns dados de pesquisa sobre o Trabalho Docente na Educação Básica no Brasil (2010), com destaque para a remuneração e carreira docente. A terceira parte do artigo se dedica a apresentar algumas considerações finais, apontando contradições, limites e desafios postos às políticas educativas no contexto atual.

Palavras-chave: Política educacional. Qualidade da educação. Remuneração docente.
Adriana Duarte

Savana Diniz Gomes Melo

Universidade Federal de Minas Gerais
This article concerns teacher's wages as one of the aspects that compose a teacher's work condition and defends it as an item of utmost importance for education quality, although not exclusive. To discuss this argument the paper is organized in three parts. The first presents the debate about education quality and teachers valorization policy, highlighting remuneration, addressing both conceptual and legal aspects, beyond academic researches. The second argues data from the research on Teaching Work in Elementary Education in Brazil (2010), highlighting remuneration and the faculty career. The third part of the article is dedicated to presenting final considerations, pointing contradictions, limits and challenges presented to educational policy in the current context.

Keywords: Educational policy. Education quality. Teacher's wages. 


\section{Introdução}

As grandes transformações processadas na sociedade brasileira, nas últimas décadas, e, inseridas em um amplo processo de reestruturação do capitalismo mundial, abrangem diversos campos, tais como: a política, a economia, a administração e a cultura na sociedade global. Esse processo compreende, o ajuste estrutural e a reestruturação produtiva, englobando, também, a reforma do aparelho de Estado, chamada de Reforma Administrativa, que reúne, no campo social, as reformas da previdência, da saúde e da educação, setores basilares para a saída da crise do capital.

No campo da educação, as alterações decorrentes das reformas empreendidas foram intensas e abarcaram a organização escolar, a organização do trabalho docente, a estrutura do sistema educativo (níveis, etapas e modalidades), responsabilidades para com a oferta, metodologias de ensino, currículo, avaliação, planejamento e gestão da educação, entre outras. Essas mudanças vieram amparadas em numerosa, fragmentada e complexa legislação, que anunciava como objetivos a ampliação do direito à educação, alargando o acesso e a melhoria da qualidade.

Associadas às mudanças do campo educacional, processaram-se, também, profundas transformações nas relações de emprego e de trabalho no setor público. A política salarial desse setor caracteriza-se por uma grande diversidade. Os vencimentos se diferenciam em função da carreira, do contrato de trabalho (efetivo ou temporário), do cargo, do regime de trabalho, do nível e da classe, do tempo de serviço, da investidura em cargos de confiança, das gratificações incorporadas, da titulação e, mais recentemente, do desempenho. (OLIVEIRA, 2007).

Entre as alterações nas relações de trabalho implantadas com a Reforma Administrativa, um dos aspectos mais controvertidos foi a quebra da estabilidade dos servidores públicos, o que, para alguns autores (ARAÚJO, 2000), implicou degeneração dos serviços públicos e o aprofundamento do fisiologismo no interior do Estado. Também a extinção da isonomia salarial, a flexibilização do sistema de remuneração e ausência de política salarial e de mecanismos de negociação coletiva foram apontados como outros graves problemas que corroboraram essa deterioração.

No campo educacional, a degeneração representaria a perda de de qualidade da educação. Contudo, contraditoriamente, a reforma educa- 
cional, empreendida no Brasil a partir de 1990, propala como um de seus objetivos prioritários a melhoria dessa qualidade.

É inegável, no entanto, que a qualidade da educação está vinculada com a própria valorização do magistério a qual implica, entre outras coisas, assegurar condições de trabalho e de salário dignos; carreira docente com possibilidade de progressão funcional; regime de trabalho; concurso público; formação e qualificação profissional; tempo remunerado para estudos, planejamento e avaliação, assegurado no contrato de trabaTho; reconhecimento social; dignidade profissional, como sinalizado por Leher (2010). Não obstante, esses elementos estão na contramão das propostas contidas na Reforma Administrativa.

Ao se aproximar da realidade do trabalho docente nas redes públicas de ensino no país, pode-se constatar a existência de diferenças gritantes entre os discursos dos reformadores e os textos das legislações relativos à valorização do magistério e aos mecanismos que se colocam, efetivamente, na prática das escolas.

Se, em tais discursos e legislações, verifica-se uma suposta afirmação da qualidade da educação e da valorização do magistério, na prática, são criados e consolidados distintos mecanismos que, vistos em seu conjunto, não somente negam tais termos como também naturalizam o quadro de degeneração que os envolve. Essa naturalização se expressa, sobremaneira, na precarização do trabalho e da remuneração dos professores; mas igualmente se expressa na naturalização da ideia de que a escola pública oferece educação de baixa qualidade.

Compreender o novo paradigma que se apresenta para a educação na atualidade é condição sine qua non para a compreensão das razões do reiterativo e persistente padrão de baixa qualidade da educação e de baixo investimento em remunerações dos professores das redes públicas de ensino. $\bigcirc$ presente artigo busca contribuir para essa dupla reflexão. 


\section{Qualidade da Educação e Valorização Docente: aspectos conceituais e legais}

A remuneração' dos professores passou a compor o conceito de valorização docente, nos documentos oficiais, desde a Constituição Federal de 1988. Esse conceito entrou na ordem do dia no Brasil quando ganhou destaque a importância da função do professor associada à qualidade da educação em meados da década de 1990.

O debate em torno da qualidade da educação no país é desafiador e complexo, e remete a identificação e compreensão de vários significados que essa expressão assume e suas implicações. Trata-se de um conceito, que é social e historicamente construído, pois sofre a influência das tradições, dos costumes, da cultura, do caráter das relações sociais vigentes, das prioridades sociais, políticas e econômicas dos projetos educacionais em disputa e de sua representatividade. (MACHADO, 2003).

Nesse contexto, governos, profissionais da educação, pais, alunos, empresários, comunidade e pesquisadores da área ${ }^{2}$ expressam suas diferentes, e, às vezes, antagônicas concepções em torno do tema. Cada um desses grupos defende uma ideia de qualidade da educação em que subjaz uma concepção de homem, de mundo e de sociedade. A partir dela, seus adeptos buscam explicar a persistente falta de qualidade da educação no país - fenômeno reiteradamente anunciado pela mídia, com respaldo dos resultados das avaliações dos estudantes e das instituições de ensino dos últimos anos - e procuram, também, defender e implantar suas propostas para a suposta superação do problema nem sempre condizentes com os requerimentos de uma educação de qualidade para todos

Para uma compreensão ampla da qualidade da educação, seria necessário considerar que esta não se define, tampouco é garantida por aspectos isolados. Ao contrário, sua efetivação depende de múltiplos determinantes, desde aqueles de ordem estrutural e histórica /desigualdade social, construção da educação como política pública, o direito à educação, entre outros), como aqueles relativos à própria organização escolar e do trabalho escolar. Neste, incluem-se as condições em que os docentes realizam o seu trabalho, sendo a remuneração um dos seus componentes fundamentais. 
Em termos legais, conforme anunciado anteriormente, a remuneração passou a compor o conceito de valorização docente disposto na Constituição da República Federativa do Brasil de 1988 (CF/1988), que englobou, em seus dispositivos, o plano de carreira para o magistério público, o ingresso via concurso público e o piso salarial profissional lart. 206, V).

Como regulamentadora do texto constitucional, a Lei $\mathrm{n}^{\circ}$ 9.394/1996, Lei de Diretrizes e Bases da Educação Nacional (LDB) de 1996 (Art. 9 , I, II, III), promulgada oito anos após a Constituição Federal (CF) de 1988, estabeleceu prazo de seis meses para que o Distrito Federal (DF), estados e municípios legislassem sobre carreira e remuneração condigna para docentes do ensino fundamental público letapa obrigatória da educação básica), visando à melhoria da qualidade do ensino. (BRASIL, 1996). Desse modo, essa relação entre remuneração e qualidade ficou estabelecida em termos legais.

A LDB, ao regulamentar a valorização docente, incluiu, para além do que estava previsto na CF/1988, aspectos referentes ao aperfeiçoamento profissional continuado com licenciamento periódico remunerado; 206 progressão funcional baseada na titulação ou na habilitação e na avaliação do desempenho; período reservado a estudos, planejamento e avaliação incluído na carga de trabalho e condições adequadas de trabaIho (inc. II, IV, V, VI, art. 67, Lei n 9.394/1996).

No entanto, essa lei deixou de regulamentar a jornada de trabalho, que sequer é citada, e o percentual de tempo reservado ao período de estudo e planejamento. $\bigcirc$ texto legal se limita a prever que esse tempo fosse incluído na carga de trabalho, noção imprecisa e difícil de ser dimensionada, considerando que está relacionada ao esforço que cada um despende no exercício do seu trabalho. (LIMA, 2010). Já a jornada é o espaço de tempo que indica - limite da duração do trabalho e define a quantidade de tempo que as pessoas se dedicam a atividades econômicas, ou seja, compreende a porção de tempo que o trabalho consome das vidas das pessoas. (DAL ROSSO, 2006).

Nesse sentido, a jornada de trabalho docente precisa contemplar o tempo que o professor desenvolve atividades com seus alunos, colegas, gestores, pais, comunidade, ou seja, tempos coletivos e individuais, com atividades inerentes ao seu trabalho (planejamento, reuniões, cursos, correções de tarefas, elaboração de exercícios e provas, entre outras), sejam elas desenvolvidas no 
interior da escola ou não. Essa questão é recolocada na ordem legal com a lei do piso em 2008, quando se prevê que 1/3 da jornada de trabalho deve ser contemplada com atividades extraclasse, aspecto que será discutido ainda neste item.

A LDB também não desenvolveu, em seu texto, o que se compreende por condições adequadas de trabalho, ficando a cargo de cada estado, município, rede dar a sua própria definição. Ora, essas condições devem ser identificadas com os recursos humanos (todos os trabalhadores que compõem as escolas); os recursos físicos e materiais (edificação, equipamentos, itens de consumo, material didático); os recursos financeiros; as relações de emprego (recrutamento e seleção, contrato de trabalho, jornada, salário, estatuto profissional, carreira, formação continuada, cobertura previdenciária), que têm influência direta na consecução do trabalho. Dessa forma, as condições de trabalho devem corresponder a variáveis que permitam caracterizar as dimensões quantitativas e qualitativas da educação.

Além das questões acima apontadas, a LDB introduziu a avaliação de desempenho, que pode ser implantada em várias redes públicas estaduais e municipais, associada ao pagamento de bonificação, muitas vezes, com reflexo nas carreiras.

Exemplos dessa assertiva podem ser constatados nos estudos de Gouveia (2012) que abrangeram municípios da Região Metropolitana de Curitiba. A autora identifica a ocorrência de alterações nos planos de carreira em todos os municípios pesquisados desde 1998, quando passou a vigorar o Fundo de Manutenção e Desenvolvimento do Ensino Fundamental e de Valorização do Magistério (Fundef) e o mesmo é observado em metade dos municípios investigados depois de 2008, com a entrada em vigor do Fundo de Manutenção e Desenvolvimento da Educação Básica e Valorização dos Profissionais da Educação (Fundeb). Tais mudanças buscaram, segundo a autora, responder às exigências das normas que estabeleceram esses fundos, mas sob a forte pressão dos governos municipais e estaduais comprimidos pelas possibilidades orçamentárias.

Entre as medidas que concorrem para contração das despesas com pessoal, evidenciam-se diferenças sobre os vencimentos iniciais dos profissionais e nas condiç̃oes de ingresso, jornadas reduzidas de hora-atividade, ampla variedade na diferenciação dos vencimentos dos profissionais com base na titulação entre outros; distorções que ferem as normas instituídas em âmbito na- 
cional, estabelecendo patamares remuneratórios de grande desigualdade. As diferenças entre o menor e o maior vencimento inicial dos professores com formação superior, em licenciatura plena, encontradas nessa pesquisa, alcançam marca de $154 \%$. Também foram encontradas jornadas de trabalho que continham 20\% de seu total dedicadas à hora-atividade. (GOUVEIA, 2012).

Registram-se, ainda, em outras localidades do país, mudanças na organização e composição dos cargos e níveis e as formas de progressão que dificultam a ascensão na carreira, que também repercutem sobre o salário. Um exemplo paradigmático é o caso da Rede Estadual de Minas Gerais, na qual também se verifica a criação de políticas salariais pautadas em subsídios, entre outras, que resultam na retração salarial, sobretudo dos professores ingressantes e anulam a carreira da forma como era concebida, com ascensões advindas do tempo de serviço e da formação. (OLIVEIRA; DUARTE, 20 12 ).

A situação se agrava quando se considera a existência de um grande contingente de professores temporários, descobertos de plano de carreira. Segundo Gouveia e Souza (2012), o Brasil registra mais de 30\% de professores sem planos de carreira, embora a LDB estabeleça essa necessidade há mais de 15 anos.

Conforme referido acima, o tema da valorização do magistério se apresenta com muitas lacunas na ordem legal, desde o texto da CF de 1988 e da LDB e em vários dispositivos legais, como a Emenda Constitucional $n^{\circ}$ 14/1996, que criou o Fundef e a EC n 53/2006, que criou o Fundeb e - Piso Salarial Profissional Nacional (PSPN) para o magistério público. $\bigcirc$ tema da valorização é tratado também no Plano Nacional de Educação (PNE/2001-2010) e no Projeto de Lei n 8.035/2010 do novo Plano Nacional de Educação (PNE/201 1-2020), que se encontra em tramitação no Senado Federal.

A Emenda Constitucional $n^{\circ}$ 14/1996 (BRASIL, 1996), que criou o Fundef (regulamentado pela Lei n ${ }^{\circ}$ 9.424/1996), destinou 60\% dos recursos à promoção de uma remuneração condigna para os professores do ensino fundamental em exercício ( $\S 5^{\circ}$, art. 60$)$, relacionando essa questão à melhoria da qualidade da educação. Ao se dirigir para os docentes do ensino fundamental, esse fundo excluiu os profissionais das demais etapas da educação básica e, segundo Davies (200 1), frustrou a possibilidade de melhoria salarial, considerando que os recursos distribuídos eram, praticamente, os mesmos gerados pela vinculação institucional, se associados ao não cumprimento pe- 
la União da lei do valor mínimo. Para Arelaro (2007), essa melhoria tímida se resumiu às redes municipais com baixa arrecadação que sequer pagavam o salário mínimo aos seus professores.

Esse fundo foi substituído pelo Fundeb, por meio da EC n 53/2006. Como o próprio nome indica, ele incluiu todos os níveis e modalidades da educação básica; aumentou o percentual de impostos vinculados de 15 para 20\%; e introduziu novos tributos não previstos no Fundef. Em relação à remuneração docente, o FUNDEB manteve o percentual de 60\% de subvinculação à remuneração dos profissionais da educação básica e criou o PSPN. (OLIVEIRA; DUARTE, 2012).

O estabelecimento do PSPN foi considerado por algumas organizações - entre elas, a Confederação Nacional dos Trabalhadores em Educação (CNTE) - como uma medida de suma importância no cenário nacional que é marcado por disparidades entre os entes federativos, uma vez que se observa uma enorme variação remuneratória dos docentes diante das desigualdades regionais. Para Vieira, o piso salarial é uma maneira de proporcionar uma remuneração inicial digna aos profissionais da educação e

[...] representa grande oportunidade para a construção das condições necessárias à estruturação do sistema nacional de educação, uma vez que, pela primeira vez em sua história, o país deixará de ter mais de cinco mil salários básicos nas carreiras dos profissionais da educação. (VIEIRA, 2012, p. 205).

A Lei $n^{\circ} 11.738 / 2008$, que regulamentou o PSPN para os profissionais do magistério público da educação básica em todo o país, revigorou - debate sobre carreira e remuneração dos professores no Brasil, aliado à discussão da qualidade da educação. Nessa lei, o piso foi fixado em $R \$$ 950,00 (novecentos e cinquenta reais) mensais, para a formação em nível médio na modalidade Normal (art. $2^{\circ}$ ); a carga horária semanal de trabalho de, no máximo, 40 horas $\left(\S 1^{\circ}\right.$, art. $\left.2^{\circ}\right)$, destinando, dentro dessa carga horária, o máximo de $2 / 3$ para o desempenho de atividades de interação com os educandos $\left(\S 4^{\circ}\right.$, art. $\left.2^{\circ}\right)$ e estipulou o prazo de $31 / 12 / 2009$ para que todos os entes federativos (União, DF, Estados e municípios) elaborassem ou adequassem seus planos de carreira (art. $6^{\circ}$. Previu, ainda, que, a partir de 2009, o piso seria atualizado, anualmente, no mesmo percentual estabelecido pelo Fundeb para o valor aluno-ano das séries iniciais do ensino fundamental urbano (§ único, art. $5^{\circ}$ ). (BRASIL, 2008). 


\section{Quadro 1}

Principais aspectos da Lei $n^{0} 11.738 / 2008$

\begin{tabular}{|l|l|}
\hline \multicolumn{1}{|c|}{ Aspectos } & \multicolumn{1}{|c|}{ LEI No $11.738 / 2008$} \\
\hline PSPN & R\$950,00 \\
\hline Atribuição & Nível médio, modalidade normal \\
\hline Referência & Vencimento inicial da carreira \\
\hline Carga horária semanal & No máximo, 40 horas \\
\hline Horas-atividades & No mínimo, um terço \\
\hline Profissionais do magistério & $\begin{array}{l}\text { Docentes e suporte à docência (inclui apo- } \\
\text { sentados) }\end{array}$ \\
\hline Implantação 2009 & 2/3 da diferença mais atualização \\
\hline Implantação 2010 & Totalidade mais atualização \\
\hline Referência para atualização & $\begin{array}{l}\text { Crescimento do valor mínimo aluno ao } \\
\text { FUNDEB }\end{array}$ \\
\hline Complementação da União & Complementação/FUNDEB \\
\hline
\end{tabular}

Fonte| Machado e Amaral (2012)

210 Cabe ressaltar que a Lei do Piso foi fruto de amplo debate ${ }^{3}$ envolvendo setores da sociedade, o Congresso Nacional e os gestores das três esferas de governo e se apresentou como resposta estatal à reivindicação histórica dos trabalhadores docentes e do movimento sindical por melhoria salarial em toda a década de 1990.

No entanto, diferenças de interpretação do texto legal levaram a disputas principalmente em torno da abrangência do piso, ou seja, o seu caráter nacional; o tempo de 1/3 da carga horária reservado à hora-atividade e os prazos para sua implantação. Assim, os governadores dos Estados de Mato Grosso do Sul, Paraná, Santa Catarina, Rio Grande do Sul e Ceará entraram com Ação Direta de Inconstitucionalidade (ADI n $4167 / 2008$ ) no Supremo Tribunal Federal (STF), contra a Lei do Piso.

Esses estados questionaram a vinculação do piso salarial ao vencimento inicial, o período de $1 / 3$ da jornada para atividades extraclasse e os prazos para implantação do piso. Para esses governadores 
[...] o impacto causado com a efetivação da medida teria repercussão negativa nos cofres das administrações estaduais, inclusive no tocante à Lei de Responsabilidade Fiscal, o que justificaria, nesta ótica, a não aplicabilidade dos dispositivos legais, de imediato. (AGUIAR, 2009, p. 254).

O STF, em 2011 , julgou improcedente a ADI n $4167 / 2008$ e reafirmou, em seu parecer, a atribuição da União de estabelecer normas gerais sobre educação. O STF declarou a Lei do Piso totalmente constitucional e reafirmou que o valor estipulado na Lei se refere ao salário-base, ou seja, não inclui bônus ou gratificações, devendo ser aplicada, imediatamente, por todos os entes federados.

No entanto, dados da CNTE de maio de 2013 mostram que a grande maioria dos estados não cumpre, na íntegra, a Lei do Piso e se utilizam de artifícios para sua não implantação, ou implantação parcial, conforme disposto no quadro abaixo.

Quadro 2

Cumprimento da Lei do Piso pelas Unidades da Federação

\begin{tabular}{|l|l|l|}
\hline Ocorrência & UF & Total - UF \\
\hline Cumpre na íntegra & AC, CE, DF, PE, TO & 05 \\
\hline Não cumpre & AL, BA, MA, PR, RS & 05 \\
\hline Cumpre somente o valor & MS, PA, PI, SC, SP & 05 \\
\hline $\begin{array}{l}\text { Não cumpre o valor } \\
\text { como vencimento }\end{array}$ & AP, RO & 02 \\
\hline $\begin{array}{l}\text { Cumpre apenas jornada } \\
\text { extraclasse }\end{array}$ & ES, GO, MT, SE & 04 \\
\hline $\begin{array}{l}\text { Cumpre a jornada e } \\
\text { aplica a proporcionali- } \\
\text { dade ao valor }\end{array}$ & RR & 01 \\
\hline $\begin{array}{l}\text { Não cumpre a jornada } \\
\text { extraclasse e aplica pro- } \\
\text { porcionalidade ao valor }\end{array}$ & MG, RN & 02 \\
\hline $\begin{array}{l}\text { Aplica proporcionalidade } \\
\text { ao valor }\end{array}$ & PB & 01 \\
\hline
\end{tabular}




\begin{tabular}{|l|l|l|}
\hline $\begin{array}{l}\text { Sem Referência de Piso e } \\
\text { jornada extra classe }\end{array}$ & AM & 01 \\
\hline Sem informação & RJ & 01 \\
\hline
\end{tabular}

Fonte | CNTE. Tabela de vencimentos, remunerações e jornadas de trabalho das carreiras de magistério público da educação básica (Redes Estaduais, maio, 20131

Segundo a CNTE $(2013)^{4}$, "[...] na maioria dos estados (e também dos municípios), a aplicação do piso tem registrado prejuízos às carreiras do magistério, ofendendo, assim, o dispositivo constitucional (art. 206, V) que preconiza a valorização dos profissionais da educação." Exemplo disso foi a fórmula encontrada pelos governos dos estados do Mato Grosso do Sul, Espírito Santo e Minas Gerais, onde se criou o chamado "subsídio", que passou a integrar ao salário-base as vantagens pessoais dos servidores desses estados. (CNTE, 2013). Com essa estratégia, o estado atinge o valor do piso, contrariando a decisão do STF e levando os sindicatos da educação a cobrar a correta aplicação do piso na carreira do magistério.

$\bigcirc$ descumprimento da Lei do Piso pelos estados e municípios sem con212 sequências para os entes federativos e as tentativas de prorrogar, ao máximo, a sua implantação reforçaram uma nova Ação Direta de Inconstitucionalidade, a ADI 4848/20 12 impetrada no STF pelos governadores de Mato Grosso do Sul, Goiás, Piauí, Rio Grande do Sul, Roraima e Santa Catarina, que, dessa vez, questionam o critério de reajuste do piso nacional. Nessa ADI, que se encontra em tramitação no STF, solicitou-se a inconstitucionalidade do art. $5^{\circ}$ (parágrafo único) da Lei do Piso, que prevê o seu reajuste com base em índice divulgado pelo MEC. O principal argumento desses governadores se refere ao índice de o reajuste do piso estar acima ao da inflação.

Há também uma polêmica na interpretação da relação entre a jornada e o piso salarial. A CNTE considera que a variação da jornada não implica variação do valor do piso, mas essa não é a interpretação de gestores de sistemas públicos de ensino, que se valem do texto da lei para aplicar a proporcionalidade à remuneração dos professores.

Obviamente, todos esses elementos relativos à carreira, à remuneração e ao piso têm criado tensões de alcance e intensidade variadas, demonstrando que, invariavelmente, repercutem sobre o trabalho docente, sobre a gestão dos sistemas e sobre a qualidade da educaçao. Contudo, torna-se necessário 
ampliar e aprofundar estudos que possibilitem identificar e analisar particularidades e generalidades existentes no país.

Convém destacar que a relação entre remuneração e qualidade da educação está presente, também, nos Planos de Estado de Educação tanto Nacional quanto estaduais e municipais. O PNE/2001-2010, por exemplo, que vigorou até 2010 , inovou em relação às legislações anteriores, pois, além de afirmar que a melhoria da qualidade não pode ocorrer sem a valorização do magistério, mencionava a necessidade de um salário competitivo com outras ocupações equivalentes em nível de formação no mercado de trabalho. (OLIVEIRA; DUARTE, 2012). No entanto, como se sabe, o percentual de gasto de $7 \%$ do PIB previsto para viabilizar as metas desse Plano foi vetado pelo presidente Fernando Henrique Cardoso, veto que foi mantido no governo Lula. Sendo assim, apesar de esse PNE adicionar um novo paradigma ao conjunto normativo relativo à remuneração docente, seus efeitos sobre ela foram inexistentes. (OLIVEIRA; DUARTE, 2012).

A Conferência Nacional de Educação (CONAE/2010), que buscou subsidiar a formulação do PNE 201 1-2020, foi palco de debates e do reconhecimento de que o financiamento é central e envolve a solução de alguns nós críticos da educação, entre eles o estabelecimento da real valorização dos trabalhadores em educação e a definição de referenciais de qualidade para todos os níveis e modalidades de educação/ensino. $\bigcirc$ documento final da CONAE/20 10 propôs um investimento mínimo do Estado em educação de $10 \%$ do PIB. Nessa conferência, a concepção de valorização do magistério público contemplava as condições de formação e profissionalização dos docentes e dos demais trabalhadores em educação, piso salarial, plano de cargos, carreira e remuneração, número máximo de alunos por turma e por professor.

$\bigcirc$ projeto do PNE do Executivo Federal - Projeto de Lei $n^{\circ}$ 8.035/2010 - foi enviado pelo governo ao Congresso em dezembro de 2010. Essa versão do PNE, em suas Metas 16 e 17, prevê valorizar os profissionais do magistério das redes públicas de educação básica por meio de formação continuada, carreira, piso e de equiparação do rendimento médio dos professores com mais de onze anos de escolaridade ao rendimento médio dos demais profissionais com escolaridade equivalente. Esse projeto, após ter recebido, aproximadamente, três mil emendas, foi aprovado pela Câmara dos Deputados em outubro de 2012. 
O Projeto de Lei aprovado na Câmara foi relatado no Senado Federal pelo senador José Pimentel, do Partido dos Trabalhadores do Estado do Ceará. Uma das principais mudanças propostas pelo relator trata da redação da meta 20, que se refere ao investimento na área da educação. $O$ projeto aprovado pela Câmara previa "[...] 10\% do Produto Interno Bruto (PIB) do País em investimento federal na Educação Pública ao final do decênio, tendo como meta intermediária $7 \%$ ao quinto ano de vigência do plano".

referido parecer substitui o termo "Educação pública" por "Educação" mediante a seguinte redação: "[...] ampliar o investimento público em Educação de forma a atingir, no mínimo, o equivalente a 10\% do Produto Interno Bruto (PIB) ao final do decênio." O relatório do PNE 201 1-2020 foi aprovado pela Comissão de Assuntos Econômicos do Senado em 14 de junho de 2013.

O texto vincula a educação aos royalties do regime de partilha e aos de concessão a partir de dezembro de 2012 e, também, especifica as ações que o governo federal poderá financiar com os recursos em âmbito nacional e internacional. A definição abrange programas como Ciências sem Fronteiras, o Programa Universidade para Todos (Prouni) e o Programa Nacional de Acesso 214 ao Ensino Técnico e Emprego (Pronatec), instituições do Sistema S, além de instituições filantrópicas. (SENADO FEDERAL, 2013 ).

A aprovação do parecer pelo Senado tem gerado polêmica. A mudança foi amplamente defendida pelo Ministério da Educação (MEC), mas, segundo interpretação do Sindicato Nacional dos Docentes das Instituições de Ensino Superior (ANDES-SN, 2013 ), esse parecer permite ao governo realizar investimentos que beneficiem as instituições privadas, o que o torna bastante preocupante. Um dos problemas apontados está no aspecto de a "[...] educação deixar de ser pública e passar a ser gratuita [...]", explica uma das coordenadoras do Grupo de Trabalho Política Educacional do ANDES-SN (GTPE) e $2^{a}$ vice-presidente da Regional do Rio de Janeiro, Elizabeth Barbosa. Outro aspecto que precisa ser visto com reservas, segundo o ANDES-SN, é a forma como foram destinados os royalties do petróleo para a educação nesse parecer, pois defende que o investimento na educação pública deve ser de responsabilidade do governo e não o vincula a uma fonte específica. (ANDES-SN, 2013).

Com o PNE20 1 1-2020 ainda tramitando no Senado Federal, foi lançado, em abril de 2013, a CONAE de 2014, que será realizada de 17 a 
21 de fevereiro de 2014 em Brasília. Essa conferência tem a finalidade de elaborar propostas para auxiliar o Distrito Federal, estados e municípios a implantar o novo PNE. A CONAE/2014 será organizada pelo Fórum Nacional de Educação (FNE), criado em 2010 com caráter permanente. $O$ FNE é composto por 35 entidades representantes da sociedade civil e do poder público. O fórum avalia os impactos da implementação do PNE e acompanha, junto ao Congresso Nacional, a tramitação de projetos legislativos referentes à política nacional de educação. O documento intitulado "Cenário da Educação Nacional" foi lançado em abril de 2013 e servirá de apoio aos debates em todas as conferências preparatórias, municipais e intermunicipais. O referido documento apresenta dados e diretrizes que servem de complemento ao documento-referência "O PNE na Articulação do Sistema Nacional de Educação - Participação Popular, Cooperação Federativa e Regime de Colaboração", publicado pelo Fórum em outubro de 2012. (MINISTÉRIO DA EDUCAÇÃO, 2012).

Nesse documento, são definidos oito eixos temáticos, sendo que o eixo seis trata da "Valorização dos Profissionais da Educação: Formação, Remuneração, Carreira e Condições de Trabalho". Nesse item, a valorização aparece com uma grande ênfase na formação docente e inclui planos de carreira e equiparação do rendimento médio do professor ao rendimento médio dos/as demais profissionais com escolaridade equivalente.

De acordo com a CNTE, que integra o FNE, os projetos de PNE 201 1-2020, aprovados na Câmara e em tramitação no Senado, não atendem, integralmente, às deliberações da primeira CONAE/2010, sobretudo no que diz respeito ao financiamento público e à implantação da referência para investimento nas diferentes etapas e modalidades (Custo Aluno Qualidade). No entanto, essa entidade aposta na disputa possível de ser realizada nas Conferências de 2014 e nas possíveis vitórias do movimento. (CNTE, 2013).

O debate e a disputa seguem em aberto assim como também estão por vir os resultados práticos da nova norma, seja sobre a qualidade da educação, seja sobre a valorização do magistério, em seu sentido amplo, contemplando seus pilares de forma equivalente. Acompanhar e participar do processo de forma coletiva, aportando argumentos teóricos e empíricos consistentes, pode contribuir para a definição e concretização de políticas alternativas. 


\section{Implicações das políticas de remuneração sobre os docentes brasileiros}

Os dados que serão apresentados neste item foram produzidos, em 2009, por meio de survey realizado em sete estados brasileiros (ES, MG, GO, PA, PR, RN e SCl no decorrer da Pesquisa "Trabalho Docente na Educação Básica no Brasil - Fase 1", coordenada pelo Grupo de Pesquisa sobre Política Educacional e Trabalho Docente - GESTRADO/UFMG. Nesse survey, foram entrevistados 8.795 sujeitos docentes de escolas urbanas da educação básica (educação infantil, ensino fundamental e ensino médio), distribuídos em 290 escolas municipais, 172 estaduais e 58 conveniadas $^{6} \mathrm{em}$ um total de 520 unidades escolares. (OLIVEIRA; VIEIRA, 2010; GESTRADO/UFMG/BANCO DE DADOSTDEBB, 2010).

Na pesquisa, consideraram-se como sujeitos docentes os profissionais que exercem atividades pedagógicas com as crianças e jovens nas escolas, sendo compreendidos pelos professores, educadores, monitores, estagiários, diretores, coordenadores, supervisores, orientadores, atendentes, auxiliares, dentre outros. Cabe registrar que, entre os respondentes, $71 \%$ possuíam o cargo de professor, mas $77 \%$ ingressaram nas escolas com esse cargo.

Os resultados do survey, considerando os sete estados participantes, mostram que 1/3 dos docentes entrevistados não prestou concurso público para o desempenho de suas atividades. Esse percentual se repete, mesmo quando elegemos somente a categoria de professor, cujo lócus de trabalho é a rede pública (municipal e estadual). Destaca-se também que $64 \%$ dos respondentes declararam seu vínculo como sendo de estatutários e $24 \%$ de temporários, os demais possuem contratos como celetistas, estagiários e outros.

Cerca de $40 \%$ dos entrevistados têm a remuneração (salário bruto) mensal abaixo de dois salários mínimos. Até 3 salários mínimos, existem 65\% dos docentes e até 4 salários mínimos, aproximadamente $80 \%$ dos profissionais. Na ocasião da pesquisa - 2009, o salário correspondia a R $\$ 465,00$. Dessa forma, $40 \%$ dos entrevistados estavam recebendo abaixo do piso salarial profissional de 2009, que era de $\mathrm{R} \$ 950,00$. É preciso considerar que a Lei do Piso estabeleceu o valor mínimo para o salário-base do professor, em nível médio, para o início da carreira. Os dados do estudo mostram que o tempo médio que os professores que participaram da pesquisa trabalham nas redes públicas é de 12 anos e que $84 \%$ dos docentes têm nível superior. 
Nessa situação, é possível ter docentes experientes e com nível superior recebendo abaixo do piso.

Outro aspecto importante e que deveria compor a remuneração é o trabalho realizado extraclasse. Essa pesquisa revelou que $72 \%$ dos docentes levam sempre ou frequentemente atividades para realizar em casa e $71 \%$ estimam que gastam cerca de 10 horas semanais para fazê-las. $\bigcirc$ quadro 2, apresentado na seção anterior deste artigo, mostra que Redes Estaduais (MG e RN) não vêm cumprindo com o dispositivo da Lei do Piso, que reserva 1/3 da jornada para esse tipo de atividade.

Os dados revelam também que $48 \%$ dos respondentes não estavam contemplados em planos de cargos e salários. A ausência dos planos de carreira ou a sua anulação, por meio da implantação de subsídios, como ocorreu em Minas Gerais, conforme mencionado no item anterior, pode se refletir em um novo paradigma para remuneração docente, baseado na produtividade. Quando a avaliação educacional e de desempenho dos professores assume centralidade e passa a ser vista como propulsoras de qualidade, a ideia que vem tomando força é que se deve induzir qualidade por meio da competitividade. (OLIVEIRA; DUARTE, 2012).

Isso reflete diretamente na remuneração e na forma de conceber a carreira docente, tradicionalmente estruturada pelos pilares da formação e do tempo de serviço. Nessa perspectiva, os salários devem ser pagos àqueles profissionais mais produtivos, ou seja, àqueles que atingem as metas individuais e coletivas estabelecidas pelas redes de educação, e devem ser pagos por meio de bônus, como premiação.

Os baixos salários e a ausência de plano de carreira desestimulam os docentes a permanecer nas redes, considerando que não se vislumbra a ascensão profissional por meio de incentivos e benefícios que thes proporcionem uma melhor remuneração. Essa situação não só provoca o abandono bem como reflete na atratividade da profissão docente. É preocupante que a média de idade apresentada pelos sujeitos da pesquisa seja de, aproximadamente, 41 anos.

Nesse sentido, tem sido observado o desinteresse dos egressos dos cursos de licenciatura, que não aspiram exercer o ofício docente, pela sua pouca atratividade, principalmente as condições precárias de trabalho, destacando-se, entre elas, os baixos salários e buscam outros horizontes mais promissores para suas vidas profissionais. A falta de professores em determinadas áreas 
(física, matemática, química e biologia) já é um termômetro dessa realidade.

Outra decorrência dos baixos salários registrados na pesquisa, aliada ao fato de $47 \%$ dos docentes pesquisados serem o principal provedor de renda em sua casa, é que os docentes precisam exercer a sua atividade em mais de uma instituição ou na mesma instituição em regime de dobra, com o objetivo de aumentar o padrão da remuneração. Nessa pesquisa, o percentual de profissionais que trabalha em outra instituição educacional é de $45 \%$; destes, $37 \%$ trabalham em duas unidades, $7 \%$ em três e $3 \%$ em quatro.

Os dados acima expostos explicitam a incompetência dos estados e municípios para implantação das políticas de valorização do magistério (concurso público, salários dignos, carreira, tempo remunerado para atividades extraclasse, entre outros aspectos) contidas na legislação e discutidas na seção anterior. Desse modo, a valorização que entrou na agenda política como fundamental para assegurar a qualidade se mostrou ineficaz para viabilizar sequer o que assegura a legislação, permanecendo condições precárias de remuneração e de carreira para os docentes brasileiros.

\section{Considerações finais}

Pelo o que foi exposto sobre a relação entre qualidade da educação e remuneração dos docentes, algumas considerações podem ser sintetizadas, assim como desafios podem ser apontados para os diferentes atores que atuam e disputam posições no campo educacional.

Registra-se, primeiramente, que, nos processos de reforma administrativa e previdenciária, ocorre a extinção de muitos benefícios resultantes de conquistas históricas dos docentes e que representavam salários indiretos.

Em relação à política salarial propriamente dita, pode-se observar que vem sendo disseminada e generalizada nos diversos sistemas de ensino do país a políitica de contenção de gastos, e a adoção da lógica de pagamento de bônus, baseada no desempenho e na produtividade, começa a tomar corpo e a se expandir.

Não raro, a precária condição salarial tem obrigado os professores a exercer mais de uma atividade profissional, conforme demontrado pela pesqui- 
sa TDEBB no item anterior, sendo significativo o número deles que trabalha em mais de um turno e em mais de uma rede. Isso, somado às intensas jornadas de trabalho dos professores na escola e à extensão das tarefas para a vida privada, restringe o tempo para se dedicar às atividades de preparação, planejamento, estudo, pesquisa, formação continuada.

Além disso, os baixos salários reduzem o acesso dos docentes a bens culturais (teatro, cinema, museus, viagens). Nesse sentido, pode-se afirmar que os baixos salários e a intensificação do trabalho estão associados também à precariedade das condições do trabalho pedagógico nas escolas. Contudo, a lógica gerencialista crescente nas escolas a partir da Reforma Administrativa e das reformas educacionais mascara essa situação, apontando os professores como únicos "responsáveis" pelos fracassos dos alunos nas avaliações externas.

Sob a forte tensão em que vivem os professores ante as múltiplas exigências que the são dirigidas e as insuficientes condições objetivas de trabalho, tem se verificado o aumento no adoecimento dos professores nos últimos anos. (ASSUNÇÃO; OLIVEIRA, 2009).

Além disso, as metas do novo PNE e a expansão da obrigatoriedade da educação que passa a abranger a faixa etária de 4 a 17 anos apontam a necessidade de ampliação dos quadros docentes. Ao desafio de efetivamente valorizar os docentes, acrescenta-se o desafio de que essa expansão ocorra com garantia de valorização dos novos docentes, ingressantes nas redes públicas de ensino.

Não é sem razão que as greves de docentes aumentam em vários estados e municípios do país, tendo como reivindicação central a questão salarial. Esses movimentos reivindicam o cumprimento da Lei do Piso, logo após - Supremo Tribunal Federal decidir que este se refere ao vencimento básico e que as gratificações e outros extras não podem ser computados.

É curioso observar que, embora expressivas, as greves - que são o último recurso para resolver conflitos entre patrões e empregados - alcancem a mídia e contem com adesões de estudantes, pais, segmentos da sociedade e se estendem por vários, dias e ou meses sem lograr qualquer solução, ainda que as reivindicações sejam reconhecidamente justas. Inflexíveis aos reclamos dos trabalhadores, os gestores dos sistemas de ensino não negociam com os trabalhadores e seguem recorrendo, durante as manifestações do conflito, a 
medidas repressivas, à judicialização da greve, à culpabilização dos trabalhadores docentes e de suas organizações sindicais pela suspensão da oferta do serviço público, à punição dos grevistas, num claro atentado à democracia. Em geral, as greves são longas e desgastantes e não raro se encerram com acordos que, posteriormente, são descumpridos pelo empregador.

Não há como negar que sem um salário digno para os docentes a qualidade do ensino fica comprometida. Até mesmo as análises dos resultados do Programa Internacional de Avaliação de Estudantes (PISA) de 2009 indicam que o melhor desempenho dos estudantes está relacionado aos salários mais altos dos professores. (OCDE, 2013).

Ao manter essa lógica de retração do Estado, perdem os docentes, desmotivados, desvalorizados, com seu trabalho desqualificado de várias formas; perde a educação; perdem os setores sociais que necessitam da escola pública; perdem os estudantes, seus pais; perdem os contribuintes e, fundamentalmente, perdem as gerações futuras. Resta indagar quem ganha e o que ganha com essa lógica.

Em suma, a relação entre salário dos professores e qualidade do 220 ensino é direta, embora não seja exclusiva. Vínculo empregatício forte, jornada de trabalho apropriada às distintas atividades da docência, quantitativo de docentes condizente com as escolas e necessidades dos sistemas de ensino, formação continuada de qualidade, entre outras corroboram esse processo.

Porém, não há dúvida sobre a importância, nesse processo, de remuneração justa e condizente com a atividade docente, embora muitos não queiram falar desse pilar, ou queiram fazer crer que investir nele seja impossível no quadro atual, ou que seja pura falácia. Tal posição não só reforça a desvalorização como oferece munição contra a adoção de políticas efetivas de valorização do magistério para além da formação, que apresentem como prioridade o aumento salarial concreto aos professores.

Mas, como afirma Enguita (1991, p. 67), "[...] a polêmica salarial tem sido apenas a parte mais visível do iceberg [...]", que, para ser revelado em sua magnitude, precisa ser enfrentado. 


\section{Notas}

1 Remuneração é a somatória dos valores recebidos pelos docentes composta pelo salário-base e toda espécie de gratificações, prêmios, bônus, entre outros benefícios, na mesma jornada para o período de um mês Salário-base é composto pelos valores estabelecidos em contrato inicial recebidos por docentes de determinada formação em troca do trabalho realizado em uma jornada discriminada no período de um mês e pela expressão. ICAMARGO, GOUVEIA, GIL, MINHOTO, 2009).

2 Ver: Dossiê "Qualidade Social da Educação", Caderno Cedes, Campinas, v. 29, n.78, p. 137288, maio/ago. 2009 e Machado (2003).

3 Projeto de Lei do Piso Salarial, transformado na Lei $n^{\circ} 11.738 / 2008$, foi resultado de dois Projetos de Lei, o PL n 619/2007 oriundo do Executivo em que foram coautores o Ministério da Educação (MEC), Conselho Nacional de Secretários de Educação (CONSED) e a União Nacional de Dirigentes Municipais de Educação (UNDIME) e o PL n 7.431/2006, texto do Senado Federal.

4 Nota relativaà tabela de vencimentos, remunerações e jornadas de trabalho das carreiras de magistério público da educação básica (Redes Estaduais) - maio/2013, disponível em: http:// www.cnte.org.br/index.php/lutas-da-cnte/piso-salarial-e-carreira.html. Acesso em: 26 jun. 2013.

5 O relatório dessesurvey está publicado em http://www.gestrado.org/ images/ pesquisas/5/ relatorio_sinopse_tdebb.pdf. Os dados utilizados nesta seção estão publicados nesse relatório e foram produzidos também a partir do Banco de Dados TDEBB, 2010 (GESTRADO, UFMG).

6 Somente a etapa da educação infantil contou com a participação de docentes da rede privada sem fins lucrativos, conveniada com o poder público.

\section{Referências}

AGUIAR, Márcia Ângela da Silva. O movimento dos educadores e sua valorização: o que há de novo em anos recentes? Revista Brasileira de Política e Administração da Educação, Recife, v. 25, n. 2, p. 249-262, maio/ago. 2009.

ARAÚJO, Ronaldo. Modelo de competência. In: FIDALGO, Fernando Selmar; MACHADO, Lucília Regina (Org.). Dicionário da educação profissional. Belo Horizonte: SETASCAD/ NETE-FAE-UFMG, 2000. p. 209-210.

ARELARO, Lisete. Fundef: uma avaliação preliminar dos dez anos de sua implantação. In: REUNIÃO ANUAL DA ASSOCIAÇÃO NACIONAL DE PÓS-GRADUAÇÃO, 30., 2007. Caxambu. Anais... ANPEd: Caxambu, 2007. 1. CD-ROM.

ASSUNÇÃO, Ada Ávila; OLIVEIRA, Dalila Andrade. Intensificação do trabalho e saúde dos professores. Educação \& Sociedade, Campinas, v. 30, n. 107, p. 349-372, maio/ago. 2009. 
BRASIL. Constituição da República Federativa do Brasil de 1988. Brasília, 2013. Disponível em: http://www. planalto.gov.br/ccivil_03/constituicao/ constitui\%C3\%A7ao.htm. Acesso em: 14 jun. 2013.

Emenda Constitucional $\mathrm{n}^{\circ}$ 14, de 12 de setembro de 1996. Modifica os arts. 34, 208, 211 e 212 da Constituição Federal e dá nova redação ao art. 60 do Ato das Disposições constitucionais Transitórias. Brasília, 2013. Disponível em: http://www.planalto.gov.br/ccivil_3/Constituicao/Emendas/Emc/emcl4.htm. Acesso em: 14 jun. 2013.

Emenda Constitucional $\mathrm{n}^{\circ}$ 53, de 19 de dezembro de 2006. Dá nova redação aos arts. $7^{\circ}$, 23, 30, 206, 208, 211 e 212 da Constituição Federal e ao art. 60 do Ato das Disposições Constitucionais Transitórias. Brasília, 2013. Disponível em: http://www. planalto.gov.br/ccivil_03/constituicao/Emendas/Emc/emc53.htm. Acesso em: 20 jun. 2013.

Ministério da Educação. Fórum Nacional de Educação. Documento-referência.

PNE na articulação do sistema nacional de educação - participação popular, cooperação Federativa e regime de colaboração. Brasília, out. 2012. Disponível em: fne.mec.gov.br/ index.php/conae-2014. Acesso em: 22 jun. 2013.

222 educação nacional. Brasília, 2012. Disponível em: http://www.planalto.gov.br/ccivil_03/ leis/L9394.htm. Acesso em: 20 jun. 2013.

Lei $\mathbf{n}^{\circ}$ 9.424, de 24 de dezembro de 1996. Dispõe sobre o Fundo de Manutenção e Desenvolvimento do Ensino Fundamental e de Valorização do Magistério, na forma prevista no art. 60, $\S 7^{\circ}$, do Ato das Disposições Constitucionais Transitórias, e dá outras providências. Brasília, 2013. Disponível em: http://www.planalto.gov.br/ccivil_03/leis/19424. htm. Acesso em: 20 jun. 2013.

Lei $\mathbf{n}^{\circ}$ 11.494, de 20 de junho de 2007. Regulamenta o Fundo de Manutenção e Desenvolvimento da Educação Básica e de Valorização dos Profissionais da Educação FUNDEB, de que trata o art. 60 do Ato das Disposições Constitucionais Transitórias; altera a Lei no 10.195, de 14 de fevereiro de 2001; revoga dispositivos das Leis nos 9.424, de 24 de dezembro de 1996, 10.880, de 9 de junho de 2004, e 10.845, de 5 de março de 2004; e dá outras providências. Brasília, 2013. Disponível em: http://www.planalto.gov. br/ccivil_03/_ato2007-2010/2007/Lei/L1 1494.htm. Acesso em: 20 jun. 2013.

Lei $\mathbf{n}^{\circ}$ 11.738, de 16 de julho de 2008. Regulamenta a alínea "e" do inciso III do caput do art. 60 do Ato das Disposições Constitucionais Transitórias, para instituir o piso salarial profissional para os profissionais do magistério público da educação básica. Brasília, 2013. 
Disponível em: hitp://www.planalto.gov.br/ccivil_03/_ato2007- 2010/2008/lei/ 11 1738.htm. Acesso em: 17 jun. 2013.

Supremo Tribunal Federal. Processo ADI/4167. Brasília, 2008. Disponível em: hitp://redir.stf.jus.br/estfvisualizadorpub/isp/ consultarprocessoeletronico/ ConsultarProcessoEletronico. jff? seqobjetoincidente=2645108. Acesso em: 17 jun. 2013.

Senado Federal. CAE aprova PNE com previsão de aumento gradual de investimentos na educação. (28 maio 2013). Disponível em: http://www.senado.gov.br/ atividade/materia/detalhes.asp?p_cod_mate=108259. Acesso em: 04 jul. 2013.

CAMARGO, Rubens Barbosa de, GOUVEIA, Andréa Barbosa, GIL, Juca. MINHOTO, Maria Angélica Pedra. Financiamento da educação e remuneração docente: um começo de conversa em tempos de piso salarial. Revista Brasileira de Política e Administração em Educação, Recife, v. 25, n. 2, p. 341-363, maio/ago. 2009.

CNTE. Confederação Nacional dos Trabalhadores da Educação. Piso Salarial e Carreira. Disponível em: hitp://www.cnte.org.br/index.php/lutas-da-cnte/piso-salarial-e-carreira. html. Brasília, maio 2013. Acesso em: 24 jun. 2013.

Confederação Nacional dos Trabalhadores em Educação. PNE e Royalties para a educação: quando e como? Disponível em: hitp://www.cnte.org.br/index.php/ comunicacao/cnte-informa/ 1380 -cnte-informa-654-20-de-maio-de-2013/1 1945-pne-eroyalties-para-a-educacao-quando-e-como.html. Brasília, 2013. Acesso em: 04 jul. 2013.

DAL ROSSO, Sadi. Jornada de trabalho, duração e intensidade. Ciência e Cultura, São Paulo, v. 58, n. 4, p. 31-34, out./dez. 2006.

DAVIES, Nicholas. O Fundef e as verbas da educação. São Paulo: Xamã, 2001.

ENGUITA, Mariano. Fernández. A ambiguidade da docência: entre o profissionalismo e a proletarização. Teoria e Educação, Porto Alegre, n. 4, p. 41-61, 1991. (Dossiê: Interpretando o Trabalho Docente).

GESTRADO. Grupo de Estudos sobre Política Educacional e Trabalho Docente. Belo Horizonte: Banco de dados TDEBB, 2010.

GOUVEIA, Andréia Barbosa e SOUZA, Ângelo Ricardo de. Financiamento da educação e carreira docente: possíveis implicações para a prática sindical. In: GOUVEIA, Andréia Barbosa; FERRAZ, Marcos. Educação e conflito: luta sindical docente e novos desafios. Curitiba: Appris, 2012. 
GOUVEIA, Andréia Barbosa. Oferta educacional e sindicalismo docente nos municípios do Primeiro Anel da Região Metropolitana de Curitiba. In: GOUVEIA, Andréia Barbosa; FERRAZ, Marcos. Educação e conflito: luta sindical docente e novos desafios. Curitiba: Appris, 2012.

LEHER, Roberto. Valorização do magistério. In: OLIVEIRA, Dalila; DUARTE, Adriana; VIEIRA, Livia. Dicionário: trabalho, profissão e condição docente. Belo Horizonte: UFMG/FAE, 2010. 1. CD-ROM.

LIMA, Francisco. Carga de trabalho. In: OLIVEIRA, Dalila Andrade; DUARTE, Adriana; VIEIRA, Livia. Dicionário: trabalho, profissão e condição docente. Belo Horizonte: UFMG/ FAE, 2010. 1. CD-ROM.

MACHADO, Lucília Regina. Necessidades Educacionais, ações planejadas e qualidade social. Revista dos Profissionais em Educação no Ensino Municipal, São Paulo, n. 1, p. 6-1 1, jan./mar. 2003.

MACHADO, Jarbas de Paula; AMARAL, Nelson Cardoso. Piso salarial e a carreira do magistério em Goiás. In: OLIVEIRA, João; OLIVEIRA, Dalila Andrade, VIEIRA, Livia Maria Fraga. Trabalho docente na educação básica em Goiás. Belo Horizonte: Fino Traço, 2012. p. $219-252$.

224 OlIVEIRA, Dalila Andrade; VIEIRA, Lívia Maria Fraga. Trabalho docente na educação básica no Brasil. Sinopse do Survey Nacional. Belo Horizonte: GESTRADO - UFMG, 2010.

OLIVEIRA, Dalila Andrade. Política educacional e a reestruturação do trabalho docente: reflexões sobre o contexto latino-americano. Educação \& Sociedade, Campinas, v. 28, n. 99, p. 355-375, maio/ago. 2007.

OLIVEIRA, Rosimar de Fátima; DUARTE, Adriana. A carreira e a remuneração dos docentes mineiros. In: DUARTE, Adriana; MELO, Savana; OLIVEIRA, Dalila Andrade; VIEIRA, Lívia. O trabalho docente na educação básica em Minas Gerais. Belo Horizonte: Fino Traço, 2012. p. 43-65.

SINDICATO NACIONAL DOS DOCENTES DAS INSTITUIÇÕES DE ENSINO SUPERIOR. Mudanças no PNE alteram proposta de investimento em educação pública. Disponível em: http://www.andes.org.br/andes/print-ultimas-noticias. andes?id=6046. Acesso em: 24 jun. 2013.

VIEIRA, Juçara Maria Dutra. Piso salarial e federalismo: muitos passos e compassos. Revista Retratos da Escola, Brasília, v. 6, n. 10, p. 199-209, jan./jun. 2012. 
Profa. Dra. Adriana Duarte Universidade Federal de Minas Gerais Faculdade de Educação Programa de Pós-Graduação da Faculdade de Educação Vice-coordenadora do Grupo de Estudos sobre Políica Educacional e Trabalho Docente | GESTRADO/FAE/UFMG

E-mail | driduarte58@gmail.com

Profa. Dra. Savana Diniz Gomes Melo Universidade Federal de Minas Gerais Faculdade de Educação Programa de Pós-Graduação da Faculdade de Educação Grupo de Estudos sobre Política Educacional e Trabalho Docente | GESTRADO/FAE/UFMG E-mail | sdgmufmg@gmail.com

Recebido 19 ago. 2013

Aceito 28 out. 2013 